\title{
Alterations of Heart Rate Variability and Heart Rate Turbulence in Patients with Dilated Alcoholic and Non-alcoholic Cardiomyopathy
}

\author{
GHEORGHE NICUSOR POP, COSMIN FAUR*, ADRIAN GOLDIS*, ANDREI BECEANU, \\ AHMED ABU-AWWAD, TUDOR CIOCARLIE \\ Victor Babes University of Medicine and Pharmacy, 2 Eftimie Murgu Sq., 300041, Timisoara, Romania
}

\begin{abstract}
The aim of this study is to document the imbalance of the autonomic nervous system (ANS), expressed by heart rate variability (HRV) and heart rate turbulence (HRT), in patients with alcoholic cardiomyopathy (ACM) in comparison to those with idiopathic cardiomyopathy (ICM) and to evidence the existing differences regarding the long term evolution of these two subgroups. We studied HRV, in time and frequency domain, and HRT in 58 patients newly diagnosed with dilated cardiomyopathy (DCM), admitted between Mar 2015 and Dec 2017 for arrhythmias and/or acute congestive heart failure (CHF) in the Cardiology Clinic of our hospital. Depending on the aetiology of DCM, patients with no other obvious aetiology were assigned to two groups: A - ACM, with history of heavy alcohol consumption and B - with ICM. We performed 24 hours Holter monitoring in patients and controls. Regarding HRV parameters in time domain, they were significantly depressed in patients with ACM, comparing to those with ICM. Referring to HRT, all patients had abnormal, positive values of turbulence onset (TO) and we documented statistically significant differences $(p<0.001)$ between the two groups. All patients had normal positive values of turbulence slope (TS). We documented, both in patients with ACM and ICM, depressed values of $H R V$ parameters in time domain, as well as pathological values of TO. During follow-up, we noticed a significant difference between patients with ACM and ICM regarding the duration of hospitalization.
\end{abstract}

Keywords: alcoholic cardiomyopathy, idiopathic cardiomyopathy, heart rhythm variability, heart rhythm turbulence

Observations from numerous epidemiologic studies have revealed in the past decades, complex associations between alcohol use and cardiovascular diseases [1-3]. Chronic, excessive alcohol consumption represents the major cause for the alcoholic cardiomyopathy (ACM), associated with congestive heart failure (CHF), arrhythmias and sudden cardiac death (SCD) [4]. The risk of developing dilated cardiomyopathy (DCM) is partially genetically determined, but it is estimated that over two-thirds of the adult population use alcohol to some extent, and more than $10 \%$ are heavy drinkers [5]. In particular, this risk is strongly modulated by the dose and pattern of alcohol consumption [2,6]. Comparing to other DCM (ischemic, idiopathic, endocrine), ACM seems to have a better prognosis in case of alcohol cessation [7-9].

Several experimental and clinical observations have shown that alterations of the autonomic nervous system (ANS), such as sympathetic activation and reduced vagal modulation, may have important proarrhythmic effects and may facilitate the onset of ventricular tachycardia/fibrillation [10]. These alterations of the ANS can be documented by alterations of heart rate variability (HRV) and heart rate turbulence (HRT), aspects debated in several studies [11,12]. HRV describes the spontaneous fluctuations in heart rate (HR) and normal RR intervals while HRT studies the sinus rhythm cycle length variation after isolated premature ventricular contractions (PVC). These methods are used in studies to estimate the sympathovagal imbalance in patients with congestive heart failure $[1,7,13]$ or after myocardial infarction [14], in order to predict increased cardiovascular risk and mortality [12-14].

The aim of our study is to analyse the alterations of HRV and HRT in patients with ACM and idiopathic cardiomyopathy (ICM) and to observe if there are significant differences regarding the evolution of these patients given that the drug therapy was as recommended by the guidelines.

\section{Experimental part}

Alcohol exerts complex effects on the heart, some of which are due to acute binge exposure and others that are chronic, long-standing, and additive [2]. The consumption of alcohol may result in myocardial damage by three basic mechanisms: a presumed direct toxic effect of alcohol and its metabolites (especially acetaldehyde), nutritional effects

*email: faur17@gmail.com, Phone: +40723962104; goldisadi@yahoo.com, Phone: +40722410712 
most commonly in association with thiamine deficiency and, rarely, toxic effects due to additives in the alcoholic beverage (cobalt). The acute effects of alcohol on the heart include a negative inotropic effect and arrhythmias, especially atrial fibrillation, and/or (rarely) ventricular ones resulting in SCD. Long-term heavy alcohol consumption induces adverse histological, cellular, and structural changes within the myocardium resulting in ACM.

The contributing mechanisms include: oxidative stress, apoptosis (programmed cell death), impaired mitochondrial bioenergetics and stress, derangements in fatty acid metabolism and transport [15] and accelerated protein breakdown. These mechanisms determine myocyte cellular changes resulting in intrinsic cell dysfunction, such as sarcoplasmic reticular dysfunction and changes in the intracellular calcium handling and myocyte loss. However, modulatory influences related to drinking patterns, genetic susceptibility, nutritional factors, ethnicity, and gender also many play a role [2]. In addition, alcohol has an important pro-arrhythmic effect responsible for the high incidence of arrhythmias and risk for SCD [16]. Acetaldehyde has been found to increase the release of catecholamine from sympathetic nerve endings or the adrenal medulla determining an increase in heart rate and even in the ectopic ventricular activity.

\section{Study group}

From all patients with DCM, admitted for arrhythmias and/or acute CHF in the cardiology clinic of our hospital between Mar 2015 and Dec 2017, we selected 58 participants with newly diagnosed DCM that has not been explained by another obvious aetiology (i.e. ischemia, hypertension, valvular or congenital heart disease, arrhythmias, diabetes mellitus, hyperthyroidism). Twenty-seven patients (48.27\%) had a history of heavy alcohol consumption (alcohol intake $>80 \mathrm{~g} /$ day, over a period of at least 5 years) and were considered to have ACM - Group A. Group B consisted of thirty-one patients $(53.44 \%)$ without significant alcoholism, which were diagnosed with ICM. They were treated according to guidelines recommendations [17] and followed for at least 12 months. Mortality, number and duration of hospitalisation were analysed.

\section{Cardiological evaluation}

after clinical examination, 12- lead electrocardiogram and chest X-ray, the diagnostic of DCM was based on the assessment of dilated cardiac cavities and reduced ejection fraction (EF) of under 39\% by echocardiography. All echocardiographic examinations were performed with an Acuson Sequoia C 512 echocardiograph, by the same echocardiographist in order to avoid inter-observer differences. Two-dimensional and M-mode echocardiography were performed in accordance with the recommendations of the American Society of Echocardiography. After a regular exam of cardiac morphology and function, we assessed the left ventricular ejection fraction (LVEF) by using the Simpson method and the estimated systolic pulmonary pressure (PAPs).

At the inclusion in the study, all patients had 24 hours Holter monitoring, performed with a Holter Labtech Cardiospy device. For the analysis of obtained data we used the Nevrokard Long-Term aHLV (L-aHRV V.5.0.0.) program. Regarding HRV, we studied the following parameters in time domain (TD): the standard deviation of all normal to normal (NN) intervals (SDNN), the standard deviation of all NN intervals occurred in 5 minutes (SDANN), the radical of the differences of mean squared NN successive intervals (RMSSD) and the HRV index (HRVTI); in frequency domain (FD): total power (TP), low frequency (LF), high frequency (HF) and LF/HF ratio. For HRT we determined the turbulence onset (TO) - early sinus acceleration after a PVC and the turbulence slope (TS) - late sinus deceleration following a PVC, according to guidelines [18].

Data analysis was performed using SPSSv.25.0 (Statistical Package for the Social Sciences, Chicago, IL, USA). Continuous variables were presented as a mean and standard deviation (SD) or median and associated quartiles (Q1, Q3) and categorical data were presented as counts (percentages). We performed descriptive and inferential statistics analysis to summarize the characteristics of the study population. To evaluate the proportion of HRV and HRT altered parameters in groups, we applied the chi-squared test $(\chi 2)$. For comparing patient groups, we used the t-student test and Mann Whitney U test. For comparing patient groups, we used the Kruskal-Wallis H test, followed by a post-hoc analysis with Mann-Whitney U test with Bonferroni correction applied. A p value of less than 0.05 was considered to indicate a statistically significance. The study was approved by the Ethics Committee of our hospital and all patients signed a written consent.

\section{Results and discussions}

Our study group consisted of 58 patients, 36 men and 22 women, aged between 37 and 69 years, newly diagnosed with DCM and admitted in the hospital for CHF or/and arrhythmias. They were divided into two subgroups: group A - included 27 patients, 19 men and 8 women, mean age $62.69 \pm 4.77$ years, with a history of heavy alcohol consumption (alcohol intake $>80 \mathrm{~g}$ /day, over a period of at least 5 years) who were considered with ACM. Group B consisted of 31 patients, 17 men and 14 women, mean age 53.73 \pm 5.69 years, without significant alcoholism and without other aetiology that could explain the presence of CMD which were diagnosed with ICM. 
Table 1

CLINICAL AND LABORATORY CHARACTERISTICS OF THE STUDY GROUPS

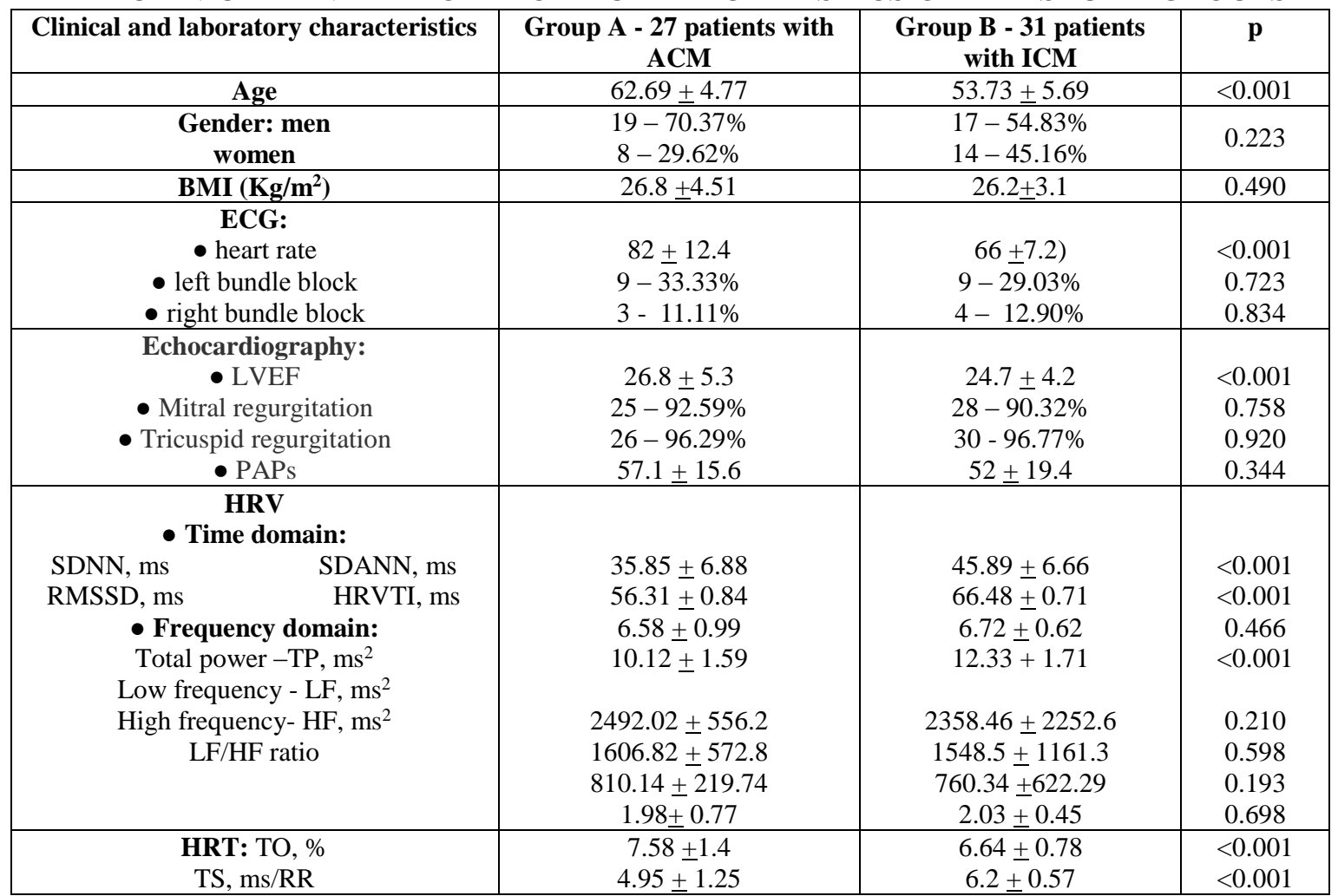

Legend: alcoholic cardiomyopathy - ACM; idiopathic cardiomyopathy - ICM; body mass index- BMI;

electrocardiography - ECG; left ventricular ejection fraction - LVEF; systolic estimated pulmonary artery pressure - PAPs; standard deviation of all normal to normal (NN) intervals - SDNN; standard deviation of all NN intervals occurred in 5 minutes - SDANN, the radical of the differences of mean squared NN successive intervals - RMSSD; HRV index - HRVTI; turbulence onset - TO; turbulence slope - TS.

All patients were evaluated clinically and subsequently, all of them had chest X-ray, electrocardiography, echocardiography and 24-hours Holter monitoring. Clinical and laboratory data are presented in table 1.

The evolution of these patients was followed for a period of 12 to 30 months, median 18 (12-22) months, table 2. Because they were newly diagnosed with CMD, 23 patients (39.65\%) were not yet receiving medical treatment. At the time of the initial evaluation, therapy with diuretics was initiated in 36 patients $(62.06 \%)$, with angiotensin-converting enzyme (ACE) inhibitors in $42(72.41 \%)$, with digoxin in 21 (36.20\%), and/or with nitrates in $7(12.06 \%)$. None of the patients was receiving beta-blockers or antiarrhythmic agents at this moment. Abstinence from alcohol was strongly recommended for all patients, but only $9(33.33 \%)$ became abstinent. During follow-up, the majority of patients were treated with ACE inhibition (91.37\%), beta-blockers $(72.41 \%)$, ivabradine $(29.31 \%)$ and/or diuretics $(70.68 \%)$ or digoxin $(56.89 \%)$ if necessary. Information regarding patients' outcomes was obtained, from rehospitalization records or by phone calls to the patients or their general practitioners, table 2 .

Table 2

EVOLUTION OF STUDY GROUPS

\begin{tabular}{|c|c|c|c|c|}
\hline \multirow{2}{*}{ Evolution } & \multicolumn{2}{|c|}{ ACM } & \multirow{2}{*}{ ICM } & \\
\cline { 2 - 3 } & Abstinent 9 & Non-abstinent -18 & & \\
\hline Number of re-hospitalization & $2(1-2)$ & $3(2-4)$ & $2(1-2)$ & 0.987 \\
\hline Days of hospitalization & $10(5-10)$ & $20(13-28.5)$ & $14(7-15)$ & $<0.001$ \\
\hline Mortality & $2-22.22 \%$ & $6-33.33 \%$ & $10-32.25 \%$ & 0.829 \\
\hline
\end{tabular}

Legend: alcoholic cardiomyopathy - ACM; idiopathic cardiomyopathy - ICM

Referring to HRV analysis in time domain, all parameters (SDNN, SDANN, RMSSD and HRVTI) were significantly depressed. Although SDNN values were highly depressed in both patient groups, they were more reduced in group A, with a statistically significant difference between the two groups $(p<0.001)$. The values of HRVTI where depressed in both groups, especially in group A, with a statistically significant difference comparing to group B $(p<0.001)$. The severe depression of SDNN and HRVTI indicates a high risk for ventricular arrhythmias. Referring to HRV parameters in frequency domain, the differences between group A and B were not statistically significant. TP was reduced in both patient groups. LF and HF were elevated in both groups, but the LF/HF ratio was between normal limits. On the analysis of HRT parameters, all patients had abnormal, positive values of TO, table 1. TS values, although normal, were significantly lower in patients with ACM ( $<<0.001)$, table 1. 
The study of HRV and HRT is a highly debated topic in the literature and is used to ascertain the influences of the ANS on the heart $[1,3,18]$. Several scientific papers have been written about their significance in various physiological states and in pathological conditions [12-14]. The sympathovagal imbalance, similar to that induced by an excess of catecholamines is a well-known compensatory mechanism in CHF $[1,2,14]$. Disertori et al documented in their study [14] that all HRV parameters, measured in time and frequency domain, decreased progressively in patients with DCM. These data highlight the reduction of vagal tone and the increase of sympathetic cardiac control in ACM, with important clinical implication taking into account that decreased HRV signifies an increased risk for arrhythmias.

The value of HRV for the prediction of ventricular arrhythmias in patients with ICM, in order to select those at high risk for prophylactic ICD implantation is a topic of debated in Grimm et al study [20]. Their findings do not support the use of HRV (SDNN) for this purpose, as well as the results of the Marburg Cardiomyopathy Study (MACAS) who did not identify HRV (SDNN) as a good predictor of major arrhythmic events in patients with ICM during $52 \pm 21$ months of follow-up. Depression of HRT parameters is considered an independent risk factor for the apparition of severe arrhythmias in patients after acute myocardial infarction and in those with CHF [3].

Patients with ACM were significantly older than those with ICM ( $<<0.001)$ and male gender prevailed. They had more frequently tachycardia $(\mathrm{p}<0.001)$, but there was no significant difference regarding the incidence of intraventricular conduction disturbances. They had a better LVEF $(\mathrm{p}<0.001)$, but PAPs values were higher, thus not statistically significant. There was no significant difference regarding treatment in both subgroups. Referring to their evolution, there were no significant differences between patients with ACM who became abstinent and ICM regarding the number of hospitalisation and mortality. Only the total duration of hospitalisation was higher in the first category. If we analyse the differences between abstinent and nonabstinent patients with ACM, the last ones had more readmissions in the hospital and of longer duration $(\mathrm{p}<0.001)$ and increased mortality.

The negative inotropic and arrhythmogenic effects of alcohol at high-dose exposure are debated in the medical literature $[1,2,9]$. Several controlled clinical studies have shown a dose-dependent depressor effect of alcohol on the LV function, an effect that progressively induces the occurrence of ACM leading to CHF and sudden cardiac death [910]. Alcoholism represents one of the most frequent causes of acquired CMD after ischemic heart disease in developed countries, being responsible for an increased morbidity and mortality among these patients. Associated pulmonary hypertension worsens the prognosis of these patients [7-8]. It is discussed that alcohol cessation or even its reduction, together with standard heart failure therapies [17] leads to a better prognosis of these patients, with reduced mortality rates [19-21]. Continuation of alcohol consumption is a negative prognostic factor, associated with further decline of LV function, increased prevalence of ventricular arrhythmias and high risk of sudden cardiac death [21-24].

\section{Conclusions}

In our study, we have documented, both in patients with ACM and ICM, depressed values of HRV parameters in time domain, as well as pathological values of TO. Although positive, TS values were lower in patients with ACM. During follow-up, we noticed a significant difference between patients with ACM and ICM regarding the duration of hospitalization, but those who became abstinent had better outcome.

\section{References}

1. URBANO-MARQUEZ A, FERNANDEZ-SOLA J, Alcohol Consumption and Heart Failure Journal of Cardiac Failure 2005 Vol. 11 No. 5 329-332.

2. PIANO MR, Alcohol's Effects on the Cardiovascular System, Alcohol Res. 2017; 38(2): $219-241$.

3. PARK SK, MOON K, RYOO JH, OH CM, CHOI JM, KANG JG, CHUNG JY, YOUNG JUNG J, The association between alcohol consumption and left ventricular diastolic function and geometry change in general Korean population European Heart Journal - Cardiovascular Imaging (2018) 19, 271-278. doi:10.1093/ehjci/jex091

4. ROSSI MA, Alcohol and malnutrition in the pathogenesis of experimental alcoholic cardiomyopathy. The Journal of Pathology, 2005; doi: 10.1002/path.1711300207.

5. GÉMES K, JANSZKY I, STRAND LB, LÁSZLÓ KD, AHNVE S, VATTEN LJ, DALEN H, MUKAMAL KJ, Light-moderate alcohol consumption and left ventricular function among healthy, middle-aged adults: the HUNT study. BMJ Open 2018;8:e020777. doi:10.1136 /bmjopen-2017-020777.

6. MOEHRING A, KRAUSE K, GUERTLER D, BISCHOF G, HAPKE U, FREYER-ADAM J, BAUMANN S, BATRA A, RUMPF HJUERGEN, ULBRICHT S, JOHN U, MEYER C, Measurement invariance of the alcohol use disorders identification test: Establishing its factor structure in different settings and across gender, Drug and Alcohol Dependence (2018), https://doi.org/10.1016/j.drugalcdep.2018.05.002

7. TUDORAN M, TUDORAN C, CIOCARLIE T, POP GN, VELIMIROVICI DE, BERCEANU-VADUVA DM, Aspects of heart failure in patients with ischemic heart disease after percutaneous coronary revascularization with Polymer-coated Drug-Eluting Stents versus Bare - Metal Stents, Mat. Plast., 56, no. 1, 2019, p. 37-40.

8. TUDORAN C, TUDORAN M, VLAD M, BALAS M, POP GN, PARV F, Echocardiographic evolution of pulmonary hypertension in female patients with hyperthyroidism, Anatol J Cardiol. 2018; 20(3): 174-181.

9. FAUCHIER L, BABUTY D, PORET P, CASSET-SENON D, AUTRET ML, COSNAY P, FAUCHIER JP, Comparison of long-term outcome of alcoholic and idiopathic dilated cardiomyopathy, European Heart Journal (2000) 21, 306-314

10. YUKSEL R, YUKSEL RN, SENGEZER T, DANE S, Autonomic cardiac activity in patients with smoking and alcohol addiction by heart rate variability analysis, Clin Invest Med 2016; 39 (6): S147-S152

11. TUDORAN M, TUDORAN C, High-risk pulmonary embolism in a patient with acute dissecting aneurysm: Case report, Nigerian Jornal of Clinical Practice, 2016; 19(6): 831-833.

12. KARPYAK VM, ROMANOWICZ M, SCHMIDT JE, LEWIS KA, BOSTWICK JM, Characteristics of heart rate variability in alcoholdependent subjects and nondependent chronic alcohol users, Alcohol Clin Exp Res, 2014;38(1):9-26. doi: 10.1111/acer.12270. 
13. TUDORAN C, TUDORAN M., PARV F, POP GN, ABU-AWWAD A, VLAD M, BALAS M, Factors influencing the evolution of pulmonary hypertension in patients with hyperthyroidism, Rev.Chim.(Bucharest), 70, no. 4, p. 1328-1332.

14. DISERTORI M, MASÈ M, RIGONI M, NOLLO G, RAVELLI F, Heart rate turbulence is a powerful predictor of cardiac death and ventricular arrhythmias in postmyocardial infarction and heart failure patients a systematic review and meta-analysis, Circ Arrhythm Electrophysiol. 2016; 9:e004610. DOI: 10.1161/CIRCEP.116.004610.)

15. TUDORAN M, TUDORAN C., VLAD M, BALAS M, ABU-AWWAD A, POP GN, Impact of therapy with L-thyroxine on the evolution of arterial and aortic stiffness in female patients with overt and subclinical hypothyroidism, Rev.Chim.(Bucharest), 70, no. 4, 2019 , p. 1372 - 1376. 16. TUDORAN M, GIURGI-ONCU C., ANDOR B., ABU-AWWAD A, POP GN, BERCEANU-VADUVA DM, TUDORAN C, Impact of therapy with selective serotonine-reuptake inhibitors on the evolution of subclinical atherosclerosis in patients with depressive disorder, Rev.Chim.(Bucharest), 70, no. 5, 2019, p. $1685-1688$.

17. PONIKOWSKI P, VOORS AA, ANKER SD, BUENO H, CLELAND JGF, COATS AJS, FALK V, GONZÁLEZ-JUANATEY JR, HARJOLA V-P, JANKOWSKA EA, JESSUP M, LINDE C, NIHOYANNOPOULOS P, PARISSIS JT, PIESKE B, RILEY JP, ROSANO GMC, RUILOPE LM, RUSCHITZKA F, RUTTEN FH, VAN DER MEER P, ESC Guidelines for the diagnosis and treatment of acute and chronic heart failure: The Task Force for the diagnosis and treatment of acute and chronic heart failure of the European Society of Cardiology (ESC). European Heart Journal, 2016; 37(7):2129-2200.

18. SASSI R, CERUTTI S, LOMBARDI F, MALIK M, HUIKURI HV, PENG CK, SCHMIDT G, YAMAMOTO Y., Advances in heart rate variability signal analysis: joint position statement by the e-Cardiology ESC Working Group and the European Heart Rhythm Association coendorsed by the Asia Pacific Heart Rhythm Society Europace 2015; 17:1341-1353.

19. GUZZO-MERELLO G, SEGOVIA J, DOMINGUEZ F, COBO-MARCOS M, GOMEZ-BUENO M, AVELLANA P, MILLAN I, ALONSO-PULPON L, GARCIA-PAVIA P, Natural history and prognostic factors in alcoholic cardiomyopathy, JACC Heart Fail. 2015 Jan;3(1):78-86. doi: 10.1016/j.jchf.2014.07.014.

20. ABU AWWAD AHMED, PREJBEANU R., VERMESAN D., BRANEA I., DELEANU B., FLORESCU S., VLAD V. D., Blood Loss Of Pedicle Subtraction Osteotomy For Sagittal Imbalance Spinal Deformity, Rev.Chim.(Bucharest), 69, no. 12, 2018, p. 3680 - 3682.

21. GRIMM W, GLAVERIS C, HOFFMANN J, MENZ V, MET N, BORN S, MAISCH B, Noninvasive arrhythmia risk stratification in idiopathic dilated cardiomyopathy: design and first results of the Marburg cardiomyopathy study, 2006 https://doi.org/10.1111/j.15408159.1998.tb01217.x.

22. GOLDBERGER JJ, SUBAČIUS H, PATEL T, CUNNANE R, KADISH AH, Sudden cardiac death risk stratification in patients with nonischemic dilated cardiomyopathy, Journal of the American College of Cardiology, 2014; 63(18): 1879-1889.

23. ABU AWWAD AHMED, PREJBEANU R., VERMESAN D., DELEANU B., IONITESCU M.., FLORESCU S., VLAD C.D., DUMITRASCU V., Dose Effect Of Local Betamethasone Injection In Low Back Pain, Rev.Chim.(Bucharest), 69, no. 9, 2018 , p. 2382 - 2384.

24. ABU-AWWAD A, FOLESCU R, POP DL, MOTOC AGM, OPREA DM, TUDORAN M, ZAMFIR CL, FAUR CI, VERMESAN D, DELEANU BN, ANDOR BC, HARAGUS HG. Morphometric characteristics of fibrocartilaginous tissue in the herniated intervertebral disc. Rom J Morphol Embryol, 2019, 60(2):629-634

$\overline{\text { Manuscript received: } 11.11 .2019}$ 